\title{
Strength Analysis of EK-18 Excavator Bucket Construction for Mounting of Anti-adhesive Devices
}

\author{
S. Zenkov \\ Mechanical Faculty \\ Bratsk State University \\ Bratsk, Russia \\ mf@brstu.ru
}

\begin{abstract}
D rigid-body model of a bucket of power shovel EK-18 was built using modern CAD (Computer Aided Design) software. A tetrahedral grid with 10-node second-order elements was chosen, and the given model was imported to APM WinMachine - model preparation preprocessor for finite element analysis. A finite element model was based on the geometrical model, imported from KOMPAS-3D to APM Studio. Calculation of the stressed-strained state of the bucket was carried out under the forces emerging while digging with "back hoe" equipment. Shift, deformation and tension charts were planned and the most and the least strained areas were pointed out. Wet coherent soil excavation deals with soil adhesion to working bodies of power shovels and leads to reduced performance. Performance decrease is caused by a reduction of useful bucket capacity and partial unloading, increased front resistance to cutting (digging) caused by wet soil adhesion to a working body, increased bucket entry resistance, increased idle time caused by necessity to clean working bodies. Also energy losses increase and quality of work drops because friction forces go up. Friction force while digging and levelling account for $30 \ldots 70$ percent of total digging resistance while performance decreases $1.2 \ldots 2$ times and more. Vibrothermal exposure creates new technological effect which involves a wider humidity range of efficient application and a reduction of friction forces. Disintegrating adhesion bonds with heating requires less driving force from the vibrator. Vibration boosts up heating of the contact layer, which reduces thermal energy losses. However, the question of piezoelectric ceramic actuators location on the excavator bucket needs to be dealt with. The most suitable spots for mounting piezoelectric ceramic devices for reducing soil adhesion to the excavator bucket were defined. Their efficiency is derived from combined (vibrothermal) methods of exposure. Such devices eliminate soil adhesion to bucket and increase efficiency of using power shovels with wet coherent soils.
\end{abstract}

Keywords-excavator bucket, 3D rigid-body model, tensions, shifts, deformations, soil adhesion

\section{INTRODUCTION}

Successful functioning of enterprises depends on output of products which should meet certain demands, an application area or purpose, cater to customer needs, conform to accepted standards and technical specifications, meet society interests, take into account environmental requirements, be available to a customer at competitive price and be cost-effective.

To deliver competitive products, an enterprise needs to release new products as soon as possible, cut production costs and improve quality. This process becomes easier with the application of modern automated design engineering systems, which streamline the whole production designing process from concept formation to prototype building and to commercializing it. Therefore, the process of developing new products becomes significantly faster without loss of quality.

Computer aided design (CAD) systems enable one to carry out tridimensional and two-dimensional geometric modelling, reverse engineering, design decision assessment, technical drawings generation.

The objective of CAD is to improve designing quality, lower material costs, reduce the time needed and prevent an increasing number of engineers who perform designing and development.

\section{RESEARCH SUBJECT}

Excavating machinery operation shows that soil freezing over and adhesion to working bodies significantly reduces machinery performance.

The above-mentioned performance reduction is caused by a reduction of useful bucket capacity and partial unloading, increased front resistance to cutting (digging) caused by wet soil adhesion to a working body, increased bucket entry resistance, increased idle time caused by necessity to clean working bodies. Also energy losses increase and quality of work drops because friction forces go up. Friction force while digging and levelling account for $30 . .70 \%$ of total digging resistance while performance decreases $1.2 \ldots 2$ times and more [1-11].

Piezoelectric ceramic actuators (transducers) are proposed as a solution to a soil adhesion problem. Such transducers provide combined (vibration and thermal) exposure and can be mounted in the areas with the strongest adhesion. This effect is based on inverse piezoelectric effect.

Combined application of vibration and heating of the working surface was researched [12]. Vibrothermal exposure causes a new technological effect which results in a wider efficient humidity range and significantly less friction force. There is less vibrator driving force required for disintegrating adhesion bonds. Vibration boosts contact layer heating, which leads to reduced thermal energy costs.

However, at this point one needs to deal with the question of proper placement of piezoelectric ceramic transducers on excavator bucket. 


\section{RESEARCH OBJECTIVE}

The given paper discusses the calculation of the stresseddeformed state of the EK-18 excavator bucket using CAD system APM WinMachine in order to locate the least stressed areas to place piezoelectric ceramic transducers.

APM WinMachine is a system for automated analysis and designing mechanical equipment and machinery constructions. The system taps into latest achievements in computational mathematics, numerical methods and programming, theoretical and experimental engineering solutions. The system meet all the requirements of state standards and regulations that control design documents execution as well as computational algorithms [13].

Despite rich functional capabilities of APM WinMachine, creating tridimensional rigid-body models of parts and complex geometry constructions in this environment is quite demanding. This disadvantage is compensated by enabling a user to import files from other systems, where creating tridimensional models is easier and takes less time. Fig. 1 presents a tridimensional model of the EK-18 excavator bucket, created using KOMPAS-3D software. The model was imported into a preprocessor of model preparation for finite element analysis APM WinMachine. Then fixing points were selected and all the loads were applied according to the chart in Fig. 2. The load pattern complies to the bucket position at the moment of digging into soil. XA, XB, YA, YB - bucket fixing (reactions of bearing), force $\mathrm{P}$ (excavator maximum digging effort), affecting the bucket via its teeth, was taken as $100 \mathrm{kN}$ in accordance with technical specifications [13].

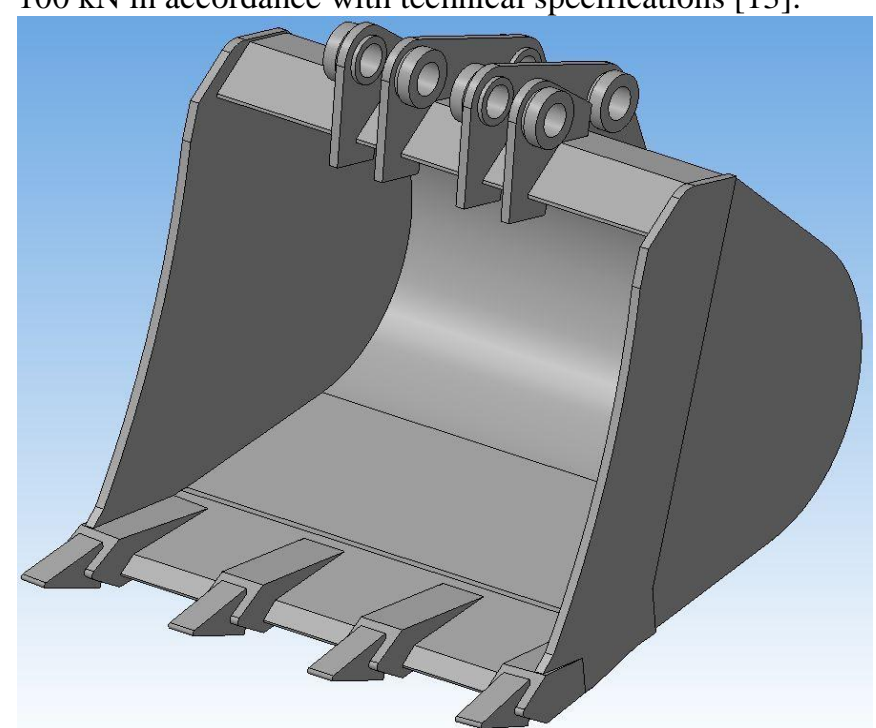

Fig. 1. A tridimensional bucket model.

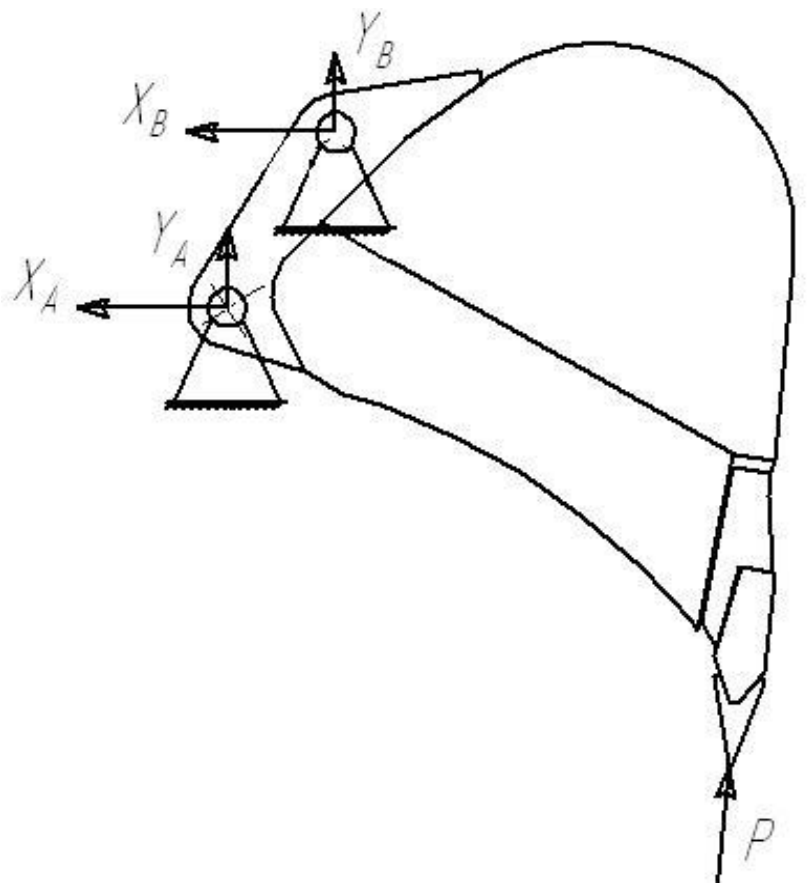

Fig. 2. A chart for forces which affect the bucket.

The finite element model was generated in APM Studio and based on the geometrical model imported from KOMPAS-3D (Fig. 3). The grid chosen was a tetrahedral one consisting of 10-node second-order elements. The number of finite elements equalled 210103, the number of nodes 60465 .

APM Studio includes tools for assembling preparation for calculation, border conditions and loads setting, as well as integrated finite element grid generators (both with fixed and varied pitch) and post-processor. This functional kit enables one to model rigid-body object and conduct complex analysis of design model behaviour in different conditions based on statics, eigenfrequencies, stability and thermal stress right in APM Studio module.

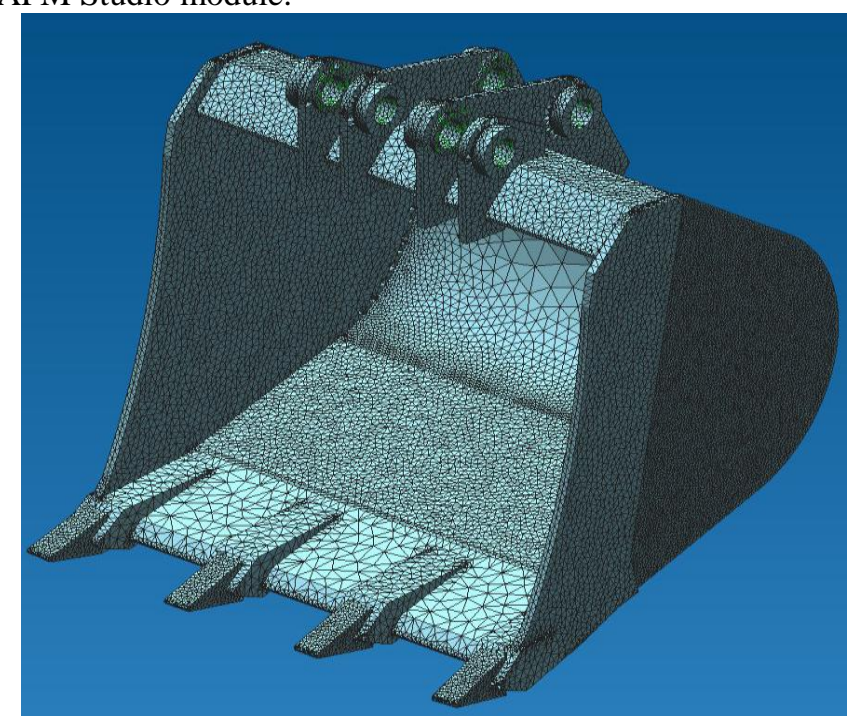

Fig. 3. Bucket breakdown into finite elements using a rigid-body modelling module in APM Studio. 
The given paper considers major loads affecting the excavator bucket for different positions. The case of maximum load application is also analysed while the load is evenly distributed along the cutting edge and each of the teeth.

Component fields of stress tensors were obtained and relative shifts in the EK-18 excavator bucket were identified using APM Studio software package for finite elements analysis under suggested problem statement within contact interaction mechanics.

\section{RESULTS ANALYSIS}

Fig. 4 shows tensions in a bucket with $25 \mathrm{kN}$ load on each of the teeth, the chart corresponds to moment of digging. Principally tensions in a bucket equal $5-10 \mathrm{mPa}$ (areas without highlight). Areas highlighted under number 1 have tensions of $30-40 \mathrm{mPa}$, under number $2-10-20 \mathrm{mPa}$, number 3 - up to $160 \mathrm{mPa}$.

The most stressed areas of the bucket are stress raisers spots where stop blocks are mounted to back wall (number 3).

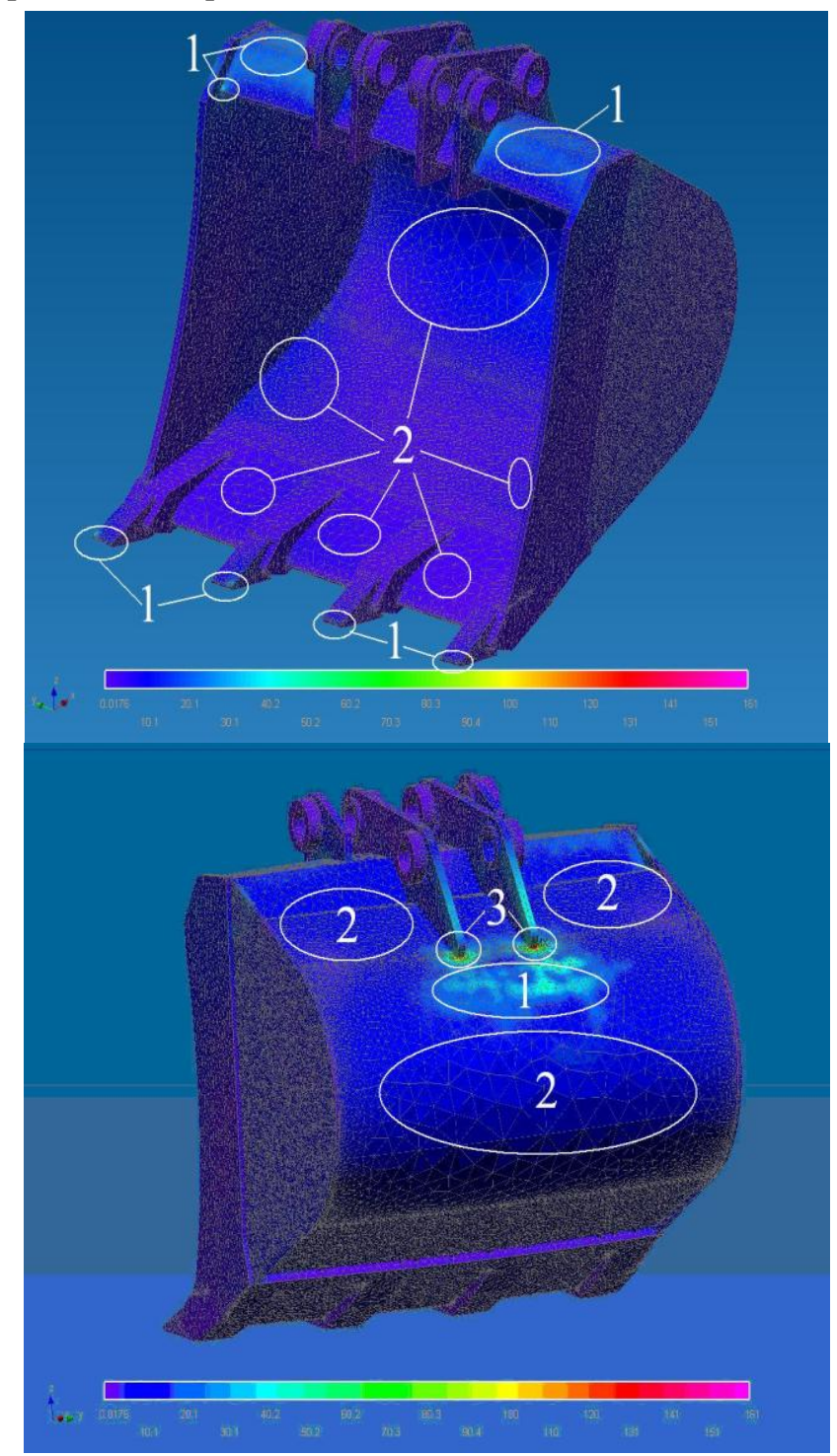

Fig. 4. A bucket stress chart.

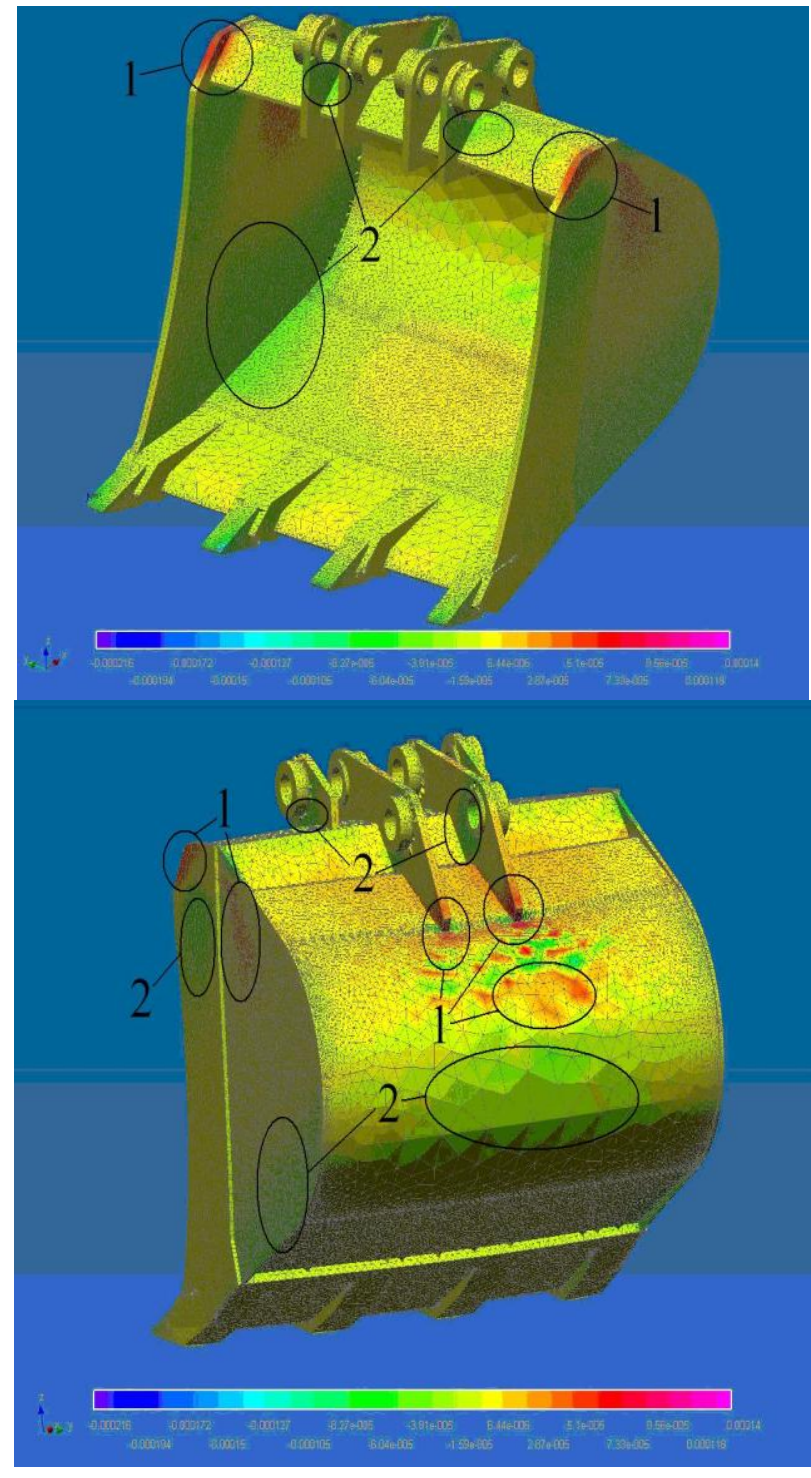

Fig. 5. A bucket intermixtures chart.

Fig. 5 shows shifts with relation to fixture points: number 1 - 1.2-1.4 mm; 2 - 0.8-1 mm; 3 - 0.6-0.7 mm; 4 - 0.1-0.2 $\mathrm{mm} ; 5-0-0.2 \mathrm{~mm}$. The biggest shift can be seen near the teeth which can be explained by concentrated load from the soil applied in these spots.

Fig. 6 shows deformations: $1-0.000070-0.000080$ stretching; 0.000040-0.000080 shrinkage. Areas without a number experience a $0.000006-0.000010$ stretch.

The results obtained present an opportunity to modify the design to balance tensions in a bucket and avoid excess tension in some areas.

Possible areas to mount piezoelectric ceramic transducers are the bucket back wall on either side of stop blocks fixing spots (Fig. 6) and areas where the bucket back wall meets the bottom. 


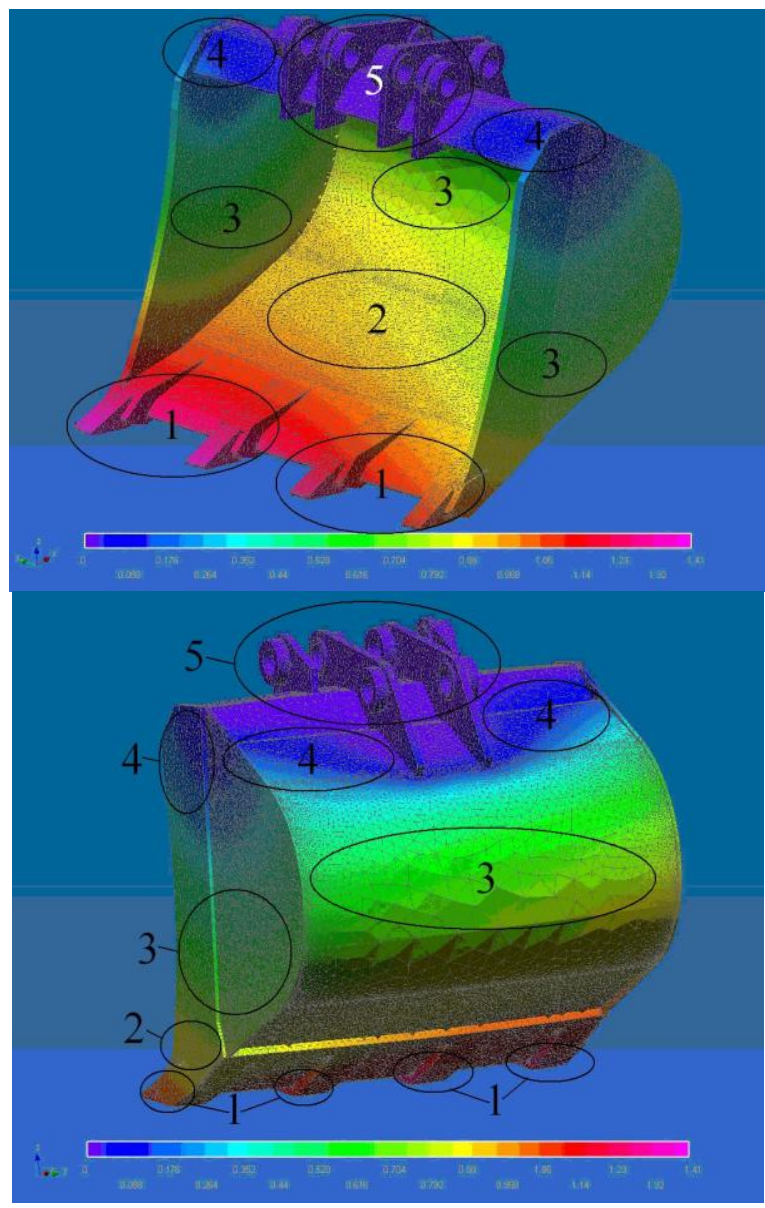

Fig. 6. A bucket deformation chart.

Fig. 7 shows the 3D model of the bucket of the excavator EK-18, the red color indicates the places most prone to sticking with the soil.

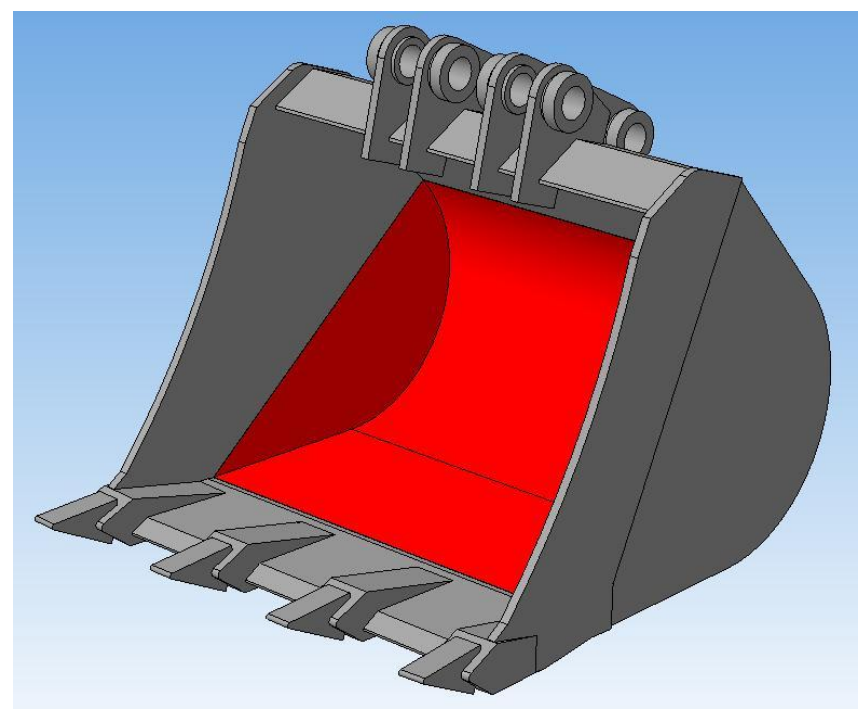

Fig. 7. A 3D Model excavator bucket
Fig. 8 shows the 3D model of the bucket of the excavator EK-18 with flexible electric heating elements ENGL-1 24V. The specific power of electric heaters is $1000 \mathrm{~W} / \mathrm{m}^{2}$.

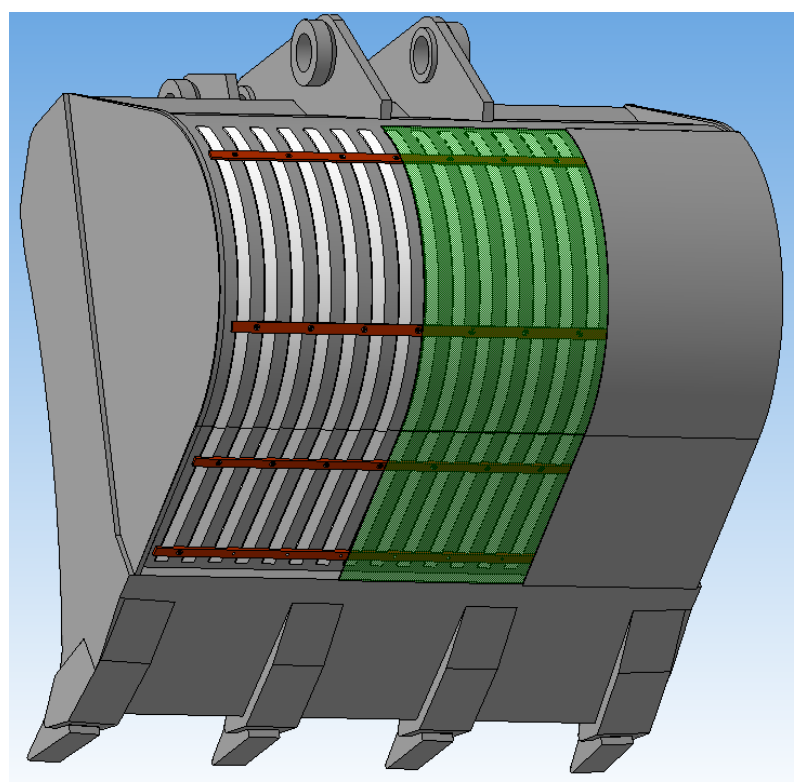

Fig. 8. A bucket with a heating element

Another technological solution is mounting a polymer antiadhesive sheet (PAS) into the EK-18 excavator bucket with a volume of $0.65 \mathrm{~m}^{3}$ via the bolt fixture (Fig. 9). The considered bucket type requires $2.1 \mathrm{~m}^{2}$ of the polymer anti-adhesive sheet. The model of a bucket with a preventive layer was constructed in the KOMPAS-3D graphic editor.

Installation of PAS to the bucket working surface is made using metalware fixtures (bolts, screws, studs etc), and also by fixing a sheet with guiding rails or gibs.

Polymer sheets installation to the working surface of a bucket should be carried out perimeter-wise, avoiding fixing it to points of maximum ground load. This fixture method also allows one to prevent new adhesion centers caused by bolt or screw heads that emerge or are insufficiently dormant into the PAS surface. Butt joints, if lining is made by marrying a few sheets, should also be directed along soil movement.

Fixture span, bolt (screw) length and a diameter need to be defined by a product engineer at the operation spot. General guidelines are as follows: the bolt diameter should be commeasurable to sheet thickness (for sheets $8 \ldots 10 \mathrm{~mm}$ thick, M10...M12 bolts (screws) can be used), fixture span $300 \ldots 500 \mathrm{~mm}$. For increased reliability matching spacers can be put under bolt heads.

The point for bolts or another type of fixture can be located using previously made sheet perforation, or vice versa - predrilled holes in metal surfaces can be used to locate points of a sheet for drilling.

When operating temperature fluctuates within the range of 23...80 degrees, holes for PAS fixture should be made with clearance to compensate the coefficient of linear thermal expansion that equals $0.2 \ldots 0,22 \mathrm{~mm} /(\mathrm{m} * \mathrm{deg})$. 

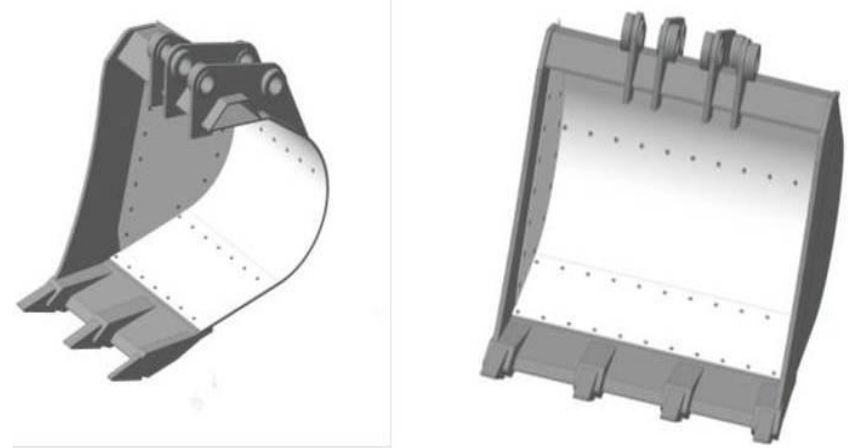

Fig. 9. A model of the EK-18 excavator bucket with anti-adhesive sheets

Heavy-walled sheets $20 \ldots 50 \mathrm{~mm}$ thick can be fixed to metalware with M16 bolts and the $300 \ldots 400 \mathrm{~mm}$ span by welding their heads to metalware and subsequent mounting of the sheets onto the bolts using pre-drilled holes and tightening the sheet core with nuts.

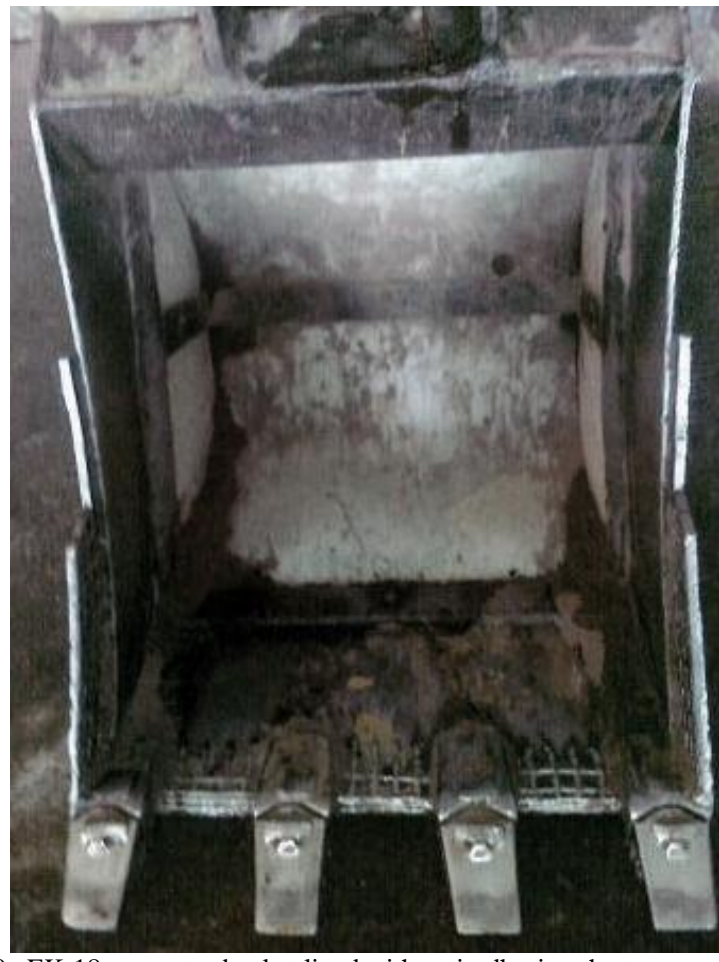

Fig. 10. EK-18 excavator bucket lined with anti-adhesive sheets

Using polymer anti-adhesive sheets allows to significantly simplify operating cycle when exploiting of soils with high adhesive properties. PPL-EI polymer coating with average shifting effort of $5 \ldots 11 \mathrm{kPa}$. The difference between shearing stress for polymer anti-adhesive sheets and steel is apparent and estimates around $17 \ldots 18 \mathrm{kPa}$, which is proved by an experiment. Polymer anti-adhesive sheets have various chemical compositions and structures with each type having been previously tested.

The proposed recommendations have been implemented by Bratsk Department of urban infrastructure, where antiadhesive sheets were fixed to EK-18 excavators buckets without using metalware (Fig. 10). To prevent lifting of antiadhesive sheets by cut soil, sheets edges have been covered with thin metal plates that do not increase soil resistance.

Using PPL-EI polymer anti-adhesive sheets with EK-18 excavator buckets for two years helped to reduce cycle duration by $17 \%$ when exploiting wet adhesive grounds under sub-zero temperatures by preventing adhesion and freezing of soil to a working body; as well as to reduce energy consumption due to improved bucket unloading.

\section{References}

[1] G. Rajaram and D. C. Erbach, "Effect of wetting and drying on soil physical properties", Journal of Terramechanics, vol. 36, pp. 39-49, 1999.

[2] V. K. Sharma, L. O. Drew, L. Nelson, "High frequency vibrational effects on soil-metal friction", Transactions of the ASAE, vol. 20, pp. 46-51, 1977.

[3] J. Zhang, Z. Sang and L. Gao "Adhesion and friction between soils and solids", Transactions of the Chinese Society of Agricultural Machinery Society of Agricultural Machinery, vol. 17, p.p. 32-40, 1986.

[4] J. Tong, L. Ren, J. Yan, Y. Ma and B. Chen, "Adhesion and abrasion of several materials against soil", International Agricultural Engineering Journal, vol. 8, pp. 1-22, 1999

[5] X. L. Wang, N. Ito, K. Kito and P. P. Garcia, "Study on use of vibration to reduce adhesion ", Journal of Terramechanics, vol.35, pp. 87-101, 1998.

[6] R. P. Zadneprovsky, Working bodies earthwork and reclamation machines and equipment for soil and high humidity materials. Moscow: Mashinostroenie, 1992, p. 176

[7] I. Buturovich and Han Duc Kim, Calculation curved concentrators, Proceedings LPI, issue 309, 1969, p.p. 69-76.

[8] R. P. Zadneprovsky, Theory of sliding friction. Volgograd: Ofset, 2005, p. 51 .

[9] L. Wang, N. Ito and K. Kito, "Study on reducing soil adhesion to machines by vibration", China Machine Press, pp. 539-545, October 1996, Proc. of the 12th Int. Conf. of ISTVS, p. 746, 1996.

[10] B. Azadegan and J. Massah, "Effect of temperature on adgesion of clay soil to steel", Agronomic Research in Moldova, vol. XLV2(150), pp.21-27, 2012 .

[11] B. Chen, D. Liu, S. Ning and Q. Cong, " Research on the reducing adhesion and scouring of soil of lugs by using unsmoothed surface electro-osmosis method", Transactions of the Chinese Society of Agricultural Engineering, vol. 11(3), pp.29-33, 1995.

[12] S. Zenkov, E. Kurmashev, A. Elokhin, O. Krasavin, "Reducing soil adhesion forces on working bodies of road-construction machinery using piezoelectric ceramic actuators (transducers)," Polytransport systems in Siberia, vol. 1, pp. 346-351, April 2009, STU, Digests 6th Scientific Conference "Polytransport systems in Siberia", p.695, 2009.

[13] A. Kozik, O. Buylov, S. Zenkov, A. Zenkov, "Finite-element research of EO-3323 excavator bucket in stressed-deformed condition," Mechanics to XXI century, pp. 143-145, May 2011, Digests of 10th International Scientific Conf. "Mechanics to XXI century," p. 412, 2011 